\title{
El derecho de acceso a la administración de justicia: una perspectiva desde la jurisprudencia de la Corte Constitucional Colombiana*
}

\author{
The right of access to the administration of justice: a perspective from the \\ jurisprudence of the Colombian Constitutional Court \\ Juliana Sánchez-Vallejo** \\ Leady Giovanna Ocampo Hoyos *** \\ Daniela González Valencia ****
}

\begin{abstract}
* Artículo inédito derivado del proyecto de investigación denominado "El desarrollo del acceso a la administración de justicia en Colombia: una visión comparativa entre la jurisprudencia de las altas cortes colombianas y los estándares de la Corte IDH en esta materia" adscrito al grupo de investigación en Derecho, Estado y Ciudadanía de la Facultad de Derecho y Ciencias Políticas y Sociales de la Universidad La Gran Colombia Armenia y cofinanciado por el Centro de Estudios de Justicia de las Américas. En el presente artículo se desarrollan los hallazgos derivados del objetivo específico que buscaba analizar el desarrollo del acceso a la justicia en la jurisprudencia constitucional colombiana.

** Magíster en Derecho Internacional de los Derechos Humanos, Justicia Penal Internacional y Derecho Internacional Humanitario. Magíster (C) en Derecho Procesal Constitucional, Especialista en Derechos Humanos y Derecho Internacional Humanitario. Abogada de la Universidad La Gran Colombia - Armenia. Miembro de la Asociación Colombiana de Derecho Procesal Constitucional (ACDPC) y directora de su Instituto de Derechos Humanos. Docente investigadora de la Universidad La Gran Colombia Armenia dentro del grupo de investigación en Derecho, Estado y Ciudadanía. . Email: sanchezvaljuliana@miugca.edu.co

*** Abogada egresada de la Facultad de Derecho y Ciencias Políticas y Sociales de la Universidad La Gran Colombia - Armenia. Integrante del semillero de investigación en Acceso a la Justicia adscrito al grupo de investigación en Derecho, Estado y Ciudadanía de la Universidad La Gran Colombia - Armenia. Correo electrónico: leady-ocampo@hotmail.com.

**** Abogada egresada de la Facultad de Derecho y Ciencias Políticas y Sociales de la Universidad La Gran Colombia - Armenia. Integrante del semillero de investigación en Acceso a la Justicia adscrito al grupo de investigación en Derecho, Estado y Ciudadanía de la Universidad La Gran Colombia - Armenia. Correo electrónico: gonzalezvaldaniela@miugca.edu.co.
\end{abstract}

Fecha de recepción: agosto de 2020

Fecha de aprobación: diciembre de 2020

Para citar este artículo / To reference this article

Sánchez-Vallejo, J.., Ocampo, L.G., González, D. (2020) El derecho de acceso a la administración de justicia: una perspectiva desde la jurisprudencia de la Corte Constitucional Colombiana Inciso, 22(2) ; 203-226

\section{Resumen}

DOI: http://dx.doi.org/10.18634/incj.22v.2i.1086

Uno de los derechos más importantes que contempla la Constitución Política de Colombia de 1991 es el acceso a la administración de justicia. Este concepto, a pesar de ser tan amplio y complejo, ha sido desarrollado exhaustivamente por la Corte Constitucional. En ese sentido, en el presente artículo se plantean los resultados de una investigación jurídica con enfoque 
mixto, que buscaba analizar el concepto, contenido, alcance y desarrollo de este derecho fundamental desde la jurisprudencia de la Corte Constitucional entre 1991 hasta el año 2017. Para este caso, se realiza el estudio del acceso a la administración de justicia en el ámbito constitucional, internacional y legal, de acuerdo con la información obtenida en la jurisprudencia constitucional, que es procesada a partir de un muestreo estadístico, y a través de una ficha de análisis de providencias. De esta manera, se encontró que, para la Corte Constitucional, el acceso a la administración de justicia es un derecho multicomprensivo que abarca tanto garantías sustanciales como procesales. Adicionalmente, se concluyó que guarda una estrecha relación con el debido proceso y se materializa desde tres perspectivas distintas: la pre procesal, la procesal y la pos procesal, empero, hay obstáculos económicos y procesales que en ciertas ocasiones impiden su concretización.

Palabras clave: Administración de justicia, derechos humanos, Corte Constitucional, jurisprudencia.

\begin{abstract}
One of the most important rights contemplated in the 1991 Political Constitution of Colombia is access to the administration of justice. This concept, despite being so broad and complex, has been exhaustively developed by the Constitutional Court. In this sense, this article presents the results of legal research with mixed approach, which seeks to define the concept, content, scope and development of this fundamental right from the jurisprudence of the Constitutional Court between 1991 to 2017. In this case, the study of access to the administration of justice is carried out, in the constitutional, international and legal sphere, in accordance with the information obtained in the constitutional jurisprudence, which is processed from a statistical sampling, and through analysis sheets. In this way, with the findings found in the jurisprudence of the closure organ of the constitutional jurisdiction, it will be showed the meaning and content that this Court has given to the studied right. At the same time, it will be presented the obstacles to the access to justice found in the constitutional jurisprudence of Colombia.
\end{abstract}

Keywords: Administration of justice, Constitutional Court, jurisprudence, human rights.

\title{
Introducción
}

El ideal de justicia ha estado presente en el pensamiento del hombre a lo largo de la historia. Es por ello, que el derecho adquiere relevancia en la sociedad, pues a través de esta disciplina se ha buscado materializar la justicia. Es así como los ordenamientos jurídicos de los Estados han pretendido alcanzar este ideal. Sin embargo, no es solamente importante la idea de justicia, sino la forma en que se accede a ella. Por esta razón, se ha establecido en el sistema normativo colombiano un derecho denominado "acceso a la administración de justicia", que se halla en el artículo 229 de la Carta Política, el cual a pesar de no estar consagrado en el acápite de los llamados derechos de primera generación, se le reconoce como un derecho fundamental que se 
concreta a través de diferentes herramientas que el Estado le proporciona a la población, para que pueda darle solución a sus conflictos, en aras de garantizar una convivencia pacífica en todo el territorio nacional. Pero, si vamos más allá, el acceso a la administración de justicia es una garantía contemplada incluso a nivel internacional, puesto que es adoptada en el artículo 25 de la Convención Americana de Derechos Humanos, otorgándole así un carácter supranacional.

Pese a lo anterior, sería utópico pensar que la aplicabilidad de la normativa tendiente a garantizar el acceso a la administración de justicia es efectiva en todos los casos, de allí la importancia de la presente investigación, cuyo objetivo general era analizar el desarrollo que ha tenido el derecho de acceso a la administración de justicia desde la jurisprudencia de la Corte Constitucional colombiana, quien actúa como cabeza de la jurisdicción constitucional y:

Conoce de manera exclusiva de los asuntos de constitucionalidad, cuyo análisis le confía la Carta Política y establece, en su condición de intérprete autorizado, las reglas jurisprudenciales sobre el alcance de las normas contenidas en la Constitución ${ }^{1}$ (Rama Judicial, s.f, párr. 3).

De esta forma, la Corte ha sido indispensable para la evolución de este derecho en Colombia, pues se ha referido a él a lo largo del tiempo, abordándolo en distintos casos, por tanto, el desarrollo de este derecho constitucional se ve materializado en las sentencias judiciales que profiere esta entidad judicial.

Es importante mencionar que, desde la perspectiva metodológica, esta investigación es de tipo jurídica, ya que partió de unos insumos jurídicos y fuentes del derecho, para llegar a unas conclusiones. También, tiene un enfoque de carácter mixto, que permite el análisis y recolección de datos cuantitativos y cualitativos, a través de procesos establecidos que permiten su vinculación. Igualmente, desde el punto de vista temporal, la investigación fue delimitada a las sentencias o providencias judiciales proferidas por la Corte Constitucional desde 1991 hasta el año 2017.

Ahora bien, todo esto no se podría realizar con un estudio meramente subjetivo; por consiguiente, para agregarle confiabilidad a la investigación, una vez se tomaron desde la relatoría de la Corte Constitucional las providencias que mencionaban los términos "acceso a la justicia" y "acceso a la administración de justicia" desde el año 1991 hasta el año 2017², se hizo un muestreo no probabilístico de carácter discrecional con afijación proporcional, que permitió seleccionar las sentencias judiciales relevantes que serían utilizadas para este estudio.

De acuerdo con lo anterior, de un total de 609 providencias de la Corte Constitucional que tratan los términos mencionados, se pudo constatar que la acción de tutela es el mecanismo en el que más se ha estudiado este derecho, tal como se vislumbra en el siguiente gráfico donde se clasifican las providencias recolectadas de acuerdo con el tipo de acción incoado:

1 Para ampliar ver: http://www.corteconstitucional.gov.co/lacorte/ (Consultado el 15 de enero de 2019).

2. La relatoría de la Corte Constitucional se encuentra disponible en: http://www.corteconstitucional.gov.co/relatoria/ 
Gráfico 1. Porcentaje por acción. Gráfico elaborado por las investigadoras.

Asimismo, en el siguiente cuadro se podrá observar el resultado del muestreo y sus respectivas proporciones, según los datos recolectados de la cantidad de providencias encontradas:

\begin{tabular}{|c|c|c|c|c|}
\hline CATEGORIAS & TOTAL & $\%$ & proyecc. Lect. & leer \\
\hline TUTELACONTRA PROVIDENCIAS JUDICIALES & 155 & $25,45 \%$ & 60 & 61 \\
\hline TUTELA & 138 & $22,66 \%$ & 53 & 54 \\
\hline TUTELA CONTRAACTO ADMINISTRATIVO & 8 & $1,31 \%$ & 3 & 5 \\
\hline TUTELA CONTRA INCIDENTE DE DESACATO & 2 & $0,33 \%$ & 1 & 2 \\
\hline ACCIONES DE CONSTITUCIONALIDAD & 199 & $32,68 \%$ & 77 & 78 \\
\hline OTRAS TUTELAS & 7 & $1,15 \%$ & 3 & 5 \\
\hline TUTELAS VS TUTELAS & 1 & $0,16 \%$ & 0 & 1 \\
\hline AUTOS & 99 & $16,26 \%$ & 38 & 38 \\
\hline TOTAL & 609 & $100,00 \%$ & 236 & 244 \\
\hline
\end{tabular}

Gráfico 2. Tabla resultado del muestreo no probabilístico discrecional con afijación proporcional. Gráfico elaborado por las investigadoras.

\begin{tabular}{|c|c|c|}
\hline total a leer según calculadora & 236 & 236,0 \\
\hline total a leer con aproximación & 244 & \\
\hline
\end{tabular}

De esta forma, una vez realizado el muestreo y con las providencias debidamente identificadas, se elaboró una ficha de análisis de información, que contenía un total de 38 preguntas alusivas a este derecho fundamental, las cuales debían ser respondidas con las opciones sí y NO. En consecuencia, cada una de las respuestas permitió analizar la manera en que la Corte Constitucional ha venido desarrollando y manejando este derecho, y también, permitió identificar cuáles han sido las circunstancias, obstáculos y limitaciones que impiden que el acceso a la administración de justicia sea ágil, oportuno y efectivo.

En virtud de lo anterior, en el presente artículo se abordará inicialmente el desarrollo constitucional del acceso a la administración de justicia desde la jurisprudencia de la Corte Constitucional, mostrando de esta manera la evolución que ha tenido desde 1991, fecha en que se instituyó la actual Carta Política que rige en Colombia hasta el 2017. Igualmente, se darán a conocer unos aportes doctrinales en relación con este derecho fundamental; para finalmente, realizar un recuento de los obstáculos tanto procesales como económicos presentados al momento de acceder a la justicia en Colombia, vislumbrados desde la jurisprudencia constitucional. 
Desarrollo del acceso a la administración de justicia desde la jurisprudencia de la Corte Constitucional

El acceso a la administración de justicia adquiere relevancia constitucional en Colombia a partir de 1991, con el nacimiento del Estado social de derecho. Esto, dado a que la extinta Constitución de 1886 contemplaba la administración de justicia como un servicio a cargo de la nación, y a partir de allí se orientaban las normas y las acciones del Estado, dejando de lado la importancia de establecer la forma de acceder a ella. Con la Carta Magna de 1991, la República de Colombia reconoció una gama amplia de derechos y garantías -entre ellos, el acceso a la administración de justicia-, y sus mecanismos de protección, como la tutela. Empero, debe destacarse el nacimiento de un organismo judicial a quien se le confió la guarda de la Constitución: la Corte Constitucional (en adelante la Corte), quien asumió desde entonces un papel muy importante, incluso trascendental, en todo el territorio nacional.

Es así como desde sus primeros años de existencia, la Corte Constitucional se pronunció respecto al acceso a la administración de justicia. De este modo, la honorable Corte se refirió a la evolución conceptual que tuvo este derecho de la Constitución de 1886 a la de 1991. En este sentido expresó:

La Constitución de 1886 en el artículo 58, establecía que "la justicia es un servicio público a cargo de la Nación". La Constitución de 1991 consagra que la administración de justicia es una función pública. [...] La Carta de 1991 modernizó el concepto en el sentido que administrar justicia ya no es un servicio más prestado por el Estado, sino que la noción de función es propia de la razón de ser del Estado. [...] Los servicios públicos son inherentes a la función social del Estado; las funciones propias del Estado, que se desprenden de su razón de ser, son legislar, ejecutar y juzgar, como lo establece el artículo 113 de la Carta Política.

En particular el artículo 229 de la Constitución consagra como principio general la garantía a toda persona de poder acceder en forma libre ante la administración de justicia. El acceso está enmarcado dentro de unos lineamientos básicos -determinados por la ley-, como son el respeto al debido proceso y a los principios en él incorporados, dependiendo del procedimiento determinado para cada tipo de actuación, como por ejemplo el término de caducidad, los requisitos de procesabilidad o los factores de competencia (Corte Constitucional, 1993, párr. 26-31).

Más adelante, la Corte Constitucional revisa el proyecto de ley estatutaria de administración de justicia, hoy Ley 270 de 1996, que estableció, entre otros aspectos, los fundamentos axiológicos que orientan la función pública de administrar justicia. Por ello, en el análisis de constitucionalidad que hace la corporación de las normas contenidas en dicha ley, resalta la trascendencia del derecho fundamental de acceso efectivo a la administración de justicia, que incluye no solo la oportunidad de que las personas puedan ir ante el juez competente para el amparo o la restitución de sus derechos, sino que también exige del juez, que en concordancia con la constitución y la ley, estudie las pruebas, llegue a un convencimiento libre, garantizando la igualdad entre las partes. De allí, la relevancia de figuras como el amparo de pobreza, la defensoría pública, los mecanismos alternativos de solución de conflictos, y la importancia de principios como la celeridad, la oralidad, la gratuidad, la eficiencia, la autonomía e independencia, entre otros, que fueron contempladas dentro de esta ley (Corte Constitucional, 1996a). 
Ahora bien, la Corte Constitucional también ha hecho referencia a la fundamentalidad del acceso a la administración de justicia, manifestando:

El acceso a la administración de justicia, se constituye para el individuo en una necesidad inherente a su condición y naturaleza, sin él los sujetos y la sociedad misma no podrían desarrollarse y carecerían de un instrumento esencial para garantizar su convivencia armónica, como es la aplicación oportuna y eficaz del ordenamiento jurídico que rige a la sociedad, y se daría paso a la primacía del interés particular sobre el general, contrariando postulados básicos del modelo de organización jurídica-política por el cual optó el Constituyente de 1991. (Corte Constitucional, 1998, párr. 95).

De esta forma, para la Corte este derecho es fundamental y tiene una primacía y protección singular por parte del Estado. Aunque su consagración expresa está en el artículo 229 de la Constitución, el artículo 228 también complementa su contenido:

[..] De igual forma, el artículo 228 de la Carta establece que la administración de justicia es función pública y se concreta en la independencia de sus decisiones, en la prevalencia del derecho sustancial y en su funcionamiento desconcentrado y autónomo. Según ha sido sostenido por la Corte, dichas características "impiden que la garantía de su acceso se vea limitada a una perspectiva formal y, en contrario, obligan a que las controversias sometidas al estudio de la jurisdicción obtengan una decisión de fondo que otorgue certidumbre sobre la titularidad y el ejercicio de los derechos objeto de litigio" (Corte Constitucional, 2016a, par. 5.1).

Asimismo, la Corte ha indicado que el derecho de acceso a la justicia también es conocido como el "derecho a la tutela judicial efectiva", lo cual significa que las personas que se encuentran en Colombia tienen la posibilidad, en igualdad de condiciones, de acudir ante los tribunales de justicia, con el fin de defender el sistema jurídico y buscar el restablecimiento y protección de sus derechos e intereses legítimos, ajustados rigurosamente a los procedimientos y garantías sustanciales y procedimentales preestablecidos en la ley (Corte Constitucional, 2002a). De igual manera, en relación con la importancia del derecho objeto de estudio ha manifestado:

El derecho de acceso a la administración de justicia constituye un pilar fundamental de la estructura de nuestro actual Estado Social de Derecho, en cuanto contribuye decididamente a la realización material de sus fines esenciales e inmediatos como son, entre otros, los de garantizar un orden político, económico y social justo, promover la convivencia pacífica, velar por el respeto a la legalidad y a la dignidad humana y asegurar la protección de los asociados en su vida, honra, bienes, creencias y demás derechos y libertades públicas (C.P. arts. $1^{\circ}$ y $2^{\circ}$ ) (Corte Constitucional, 2002ª́, pár. 6.2).

Por tal motivo, este derecho del que son titulares tanto las personas naturales, como las jurídicas, obliga a las autoridades, garantes de los derechos de las personas y que ostentan el poder coercitivo del Estado, a fomentar un acceso real y efectivo a los particulares, estableciendo las condiciones para ello, esto, por cuanto el artículo 229 de la carta lo establece como imperativo.

Asimismo, en esta sentencia, la Corte Constitucional (2002a) hace énfasis en la consagración internacional de este derecho fundamental, pues señala : "El fundamento del derecho a la protección judicial efectiva no solo se encuentra en los artículos 1, 2, 29 y 229 de la Constitución Política", sino que también hay que considerar el derecho internacional, específicamente, 
los tratados y convenciones sobre derechos humanos que han sido firmadas y aprobadas por Colombia -en concordancia con el artículo 93 de la Constitución Política-. Verbigracia, la Convención Americana sobre Derechos Humanos, en su artículo 25 declara expresamente:

Toda persona tiene derecho a un recurso sencillo y rápido o a cualquier otro recurso efectivo ante los jueces o tribunales competentes, que la ampare contra actos que violen sus derechos fundamentales reconocidos por la Constitución, la ley o la presente Convención, aun cuando tal violación sea cometida por personas que actúen en ejercicio de sus funciones oficiales (Organización de Estados Americanos, 1969, art. 25).

De igual manera, el Pacto Internacional de Derechos Civiles y Políticos en su artículo 14 señala el derecho del ser humano a ser escuchado púbicamente ante un tribunal competente, que cuente con independencia e imparcialidad y que haya sido establecido por la ley, contando con todas sus garantías, en el trámite judicial de alguna acusación penal que sea formulada en su contra o para efectos de determinar sus derechos u obligaciones civiles (Organización de Naciones Unidas, 1966).

En torno a la consagración internacional del acceso a la administración de justicia, la Corte ha analizado, por ejemplo, el rol de la Corte Penal Internacional y el principio de complementariedad, que implica que las personas pueden acudir a esta corte internacional, bajo ciertos parámetros, luego de agotar todos los recursos que contempla la ley ante la jurisdicción nacional, respecto de los crímenes más graves que se encuentran en el derecho internacional (Estatuto de Roma), garantizando de esta forma, el efectivo acceso a la justicia en una lucha contra la impunidad (Corte Constitucional, 2002b).

En este mismo sentido, para la Corte: “Los sistemas regionales de protección de derechos humanos han establecido dos criterios específicos con los que deben cumplir los recursos para que haya una garantía verdadera del acceso a la justicia" (Corte Constitucional, 2015a), haciendo alusión a la evaluación conjunta que ha hecho la Corte Interamericana de Derechos Humanos (en adelante Corte IDH) de los artículos 8 y 25 de la Convención Americana sobre Derechos Humanos, que consagran respectivamente las garantías del debido proceso y el acceso a la justicia y a un recurso judicial efectivo. De este modo, cuando se presentan violaciones de derechos humanos, donde resulta responsable internacionalmente Colombia, es imprescindible para la Corte IDH hacer alusión a la inevitable relación entre estos dos postulados. Por tal motivo, en dicha providencia, la Corte Constitucional (2015a) hace referencia a varios casos donde la Corte Interamericana aborda esta postura, como el caso de la masacre de Puerto Bello contra Colombia, la masacre de Rochela, Escué Zapata, Itüango, entre otras.

Por otro lado, a lo largo de sus consideraciones, la Corte Constitucional (1996b) establece una relación de este derecho con el debido proceso, mencionando que hace parte de su núcleo esencial y que, por tanto, es un derecho fundamental de aplicación inmediata. Adicionalmente, señala que al garantizar el derecho al debido proceso imprescindiblemente hablamos de la existencia del acceso a la administración de justicia, pues de otra forma las garantías sustanciales y procesales que contempla la ley no se podrían asegurar. Vale la pena clarificar que se trata de un derecho complejo que también está vinculado con principios como la igualdad, la libertad y la 
dignidad, por lo que es:

Un derecho medular de contenido múltiple o complejo, cuyo marco jurídico de aplicación compromete, en un orden lógico: (i) el derecho de acción o de promoción de la actividad jurisdiccional, el cual se concreta en la posibilidad que tiene todo sujeto de ser parte en un proceso y de utilizar los instrumentos que allí se proporcionan para plantear sus pretensiones al Estado, sea en defensa del orden jurídico o de sus intereses particulares; (ii) el derecho a que la promoción de la actividad jurisdiccional concluya con una decisión de fondo en torno a las pretensiones que han sido planteadas; (iii) el derecho a que existan procedimientos adecuados, idóneos y efectivos para la definición de las pretensiones y excepciones debatidas; (iv) el derecho a que los procesos se desarrollen en un término razonable, sin dilaciones injustificadas y con observancia de las garantías propias del debido proceso y, entre otros, (v) el derecho a que subsistan en el orden jurídico una gama amplia y suficiente de mecanismos judiciales -acciones y recursos- para la efectiva resolución de los conflictos (Corte Constitucional, 2002a, párr. 6.6).

Finalmente, respecto a la configuración legal del acceso a la administración de justicia, la Corte señala que es el legislador quien establece su regulación respetando su núcleo esencial. En este sentido, el desarrollo legal de este derecho debe encaminarse en asegurar el ámbito jurídico de aplicación, que comprende: el derecho de acción, que hace referencia a la posibilidad de acceder ante un juez o tribunal imparcial; el derecho a obtener la sentencia que resuelve las pretensiones formuladas, en concordancia con la normatividad vigente y en caso tal, el derecho a que la decisión adoptada sea cumplida de manera efectiva (Corte Constitucional, 1996b).

Ahora bien, el alcance del derecho fundamental de acceso a la administración de justicia, es decir, hasta dónde llega la esfera de protección del derecho, ha sido abordado por la jurisprudencia constitucional en múltiples ocasiones; verbigracia, se encuentra la sentencia T-1044 de 2004, donde la Corte Constitucional menciona que este derecho se exterioriza no solo a través del derecho de acción, sino también cuando el individuo acude a los mecanismos alternativos de resolución de conflictos, tales como la conciliación o el arbitraje. Igualmente, esta corporación expresa que el acceso a la administración de justicia garantiza a sus titulares: "Contar con procedimientos idóneos y efectivos para la determinación legal de los derechos y las obligaciones, lo cual impone claras obligaciones positivas para el Estado" (Corte Constitucional, 2004a). De esta forma, la Corte hace especial énfasis en algunas garantías que están integradas en el acceso a la justicia, a saber:

- La resolución de las controversias en un plazo razonable, sin que existan dilaciones injustificadas y con observancia del debido proceso (Corte Constitucional, 2004a). En este punto, resulta pertinente hacer alusión a la creación de procesos como el monitorio, que fue concebido con el fin de cumplir con ese pilar de la celeridad en el acceso a la administración de justicia. Por ello, la Corte menciona que este proceso declarativo especial es una forma de facilitar el acceso a la justicia (Corte Constitucional, 2013a), e incluso:

(...) se constituye en un procedimiento de acceso a la justicia para acreedores de obligaciones de mínima cuantía, que en la costumbre informal de sus transacciones dinerarias no documentan sus créditos en títulos ejecutivos, sin que por ello se les deba someter a un proceso judicial extenso y formal que desvanezca la eficiencia de la administración de justicia. (Corte Constitucional, 2016b, párr. 22.2). 
- La creación de mecanismos que posibiliten el acceso a la justicia de las personas que tienen escasos recursos (Corte Constitucional, 2004a). En este punto, no podría obviarse el amparo de pobreza, frente al cual el tribunal constitucional señala que es "una institución procesal" que permite el acceso a la administración de justicia de todos los que no pueden sufragar los gastos que implica tener un abogado que pueda representar y defender sus intereses en las diferentes instancias judiciales (Corte Constitucional, 2016c).

-La existencia de un sistema de administración de justicia que brinde una cobertura en todo el territorio nacional, a todas las personas (Corte Constitucional, 2004a). Esto último, se puede entender también en relación con la garantía del acceso a la justicia de todos los que intervienen en los procesos judiciales, lo que se ha logrado gracias a la figura del curador ad litem, que ha sido objeto de diversos pronunciamientos por parte de la Corte Constitucional. En este orden de ideas, en sentencias como la C-369 de 2014 y la C-083 de 2014 se resalta su importancia, pues, a través del curador ad litem, se garantiza el acceso a la administración de justicia de la parte del proceso que se encuentra ausente y debe ser representada, asegurando así el derecho de defensa.

-La materialización de este derecho también se da mediante métodos alternos de solución de conflictos (Corte Constitucional, 2004a). La Corte ha destacado el rol de la conciliación, pues con ella se busca lograr una convivencia pacífica, que es uno de los fines constitucionales del Estado social de derecho. Igualmente, permite que los interesados participen de manera directa en la solución de sus controversias, por tanto, es otra forma de hacer efectivo el derecho de acceso a la administración de justicia, adicionalmente, contribuye con la descongestión judicial (Corte Constitucional, 2013b). No obstante, la conciliación no es el único mecanismo de solución de conflictos que ha tenido relevancia en la jurisprudencia constitucional, también, se ha estudiado el arbitramento, entendido como: "Un recurso que garantiza el acceso a la administración de justicia." [...] ya que el arbitramento, "es uno de los instrumentos autorizados para que los particulares puedan administrar justicia” (Corte Constitucional, 2004b).

Respecto al contenido del derecho a la administración de justicia, la Corte Constitucional (2013c) ha considerado que este se resume en las siguientes obligaciones: 1) la obligación de respetar este derecho por parte del Estado, quien debe impedir que se obstaculice el acceso o la realización de la justicia y debe abstenerse de adoptar medidas que resulten discriminatorias, por motivos bien sea de género, nacionalidad o posición social; (2) la obligación de proteger que implica que el Estado no puede permitir que terceros interfieran en el acceso a la administración de justicia de las demás personas; y 3) la obligación de realizar, que incluye el deber estatal de proveer las condiciones para que las personas puedan gozar efectivamente del derecho.

Ahora bien, retomando el alcance del derecho, y particularmente, frente al cumplimiento de las sentencias judiciales, se ha expresado:

El acceso a la justicia no se agota en la posibilidad de acudir ante la administración de justicia para plantear un problema jurídico, ni en su resolución, sino que implica, también, que "se cumpla de manera efectiva lo ordenado por el operador jurídico y se restablezcan los derechos lesionados". Dada la relevancia del cumplimiento de las providencias judiciales para el derecho fundamental de acceder a la justicia, en algunas oportunidades este tribunal to ha amparado, de manera excepcional, por medio de la acción de tutela, "bajo el entendido de que la administración de justicia, además de expresarse en el respeto a las garantías establecidas en el desarrollo de un 
proceso, se manifiesta en el hecho de que las decisiones que se tomen dentro del mismo tengan eficacia en el mundo jurídico y que la providencia que pone fin al proceso produzca todos los efectos a los que está destinada" (Corte Constitucional, 2014a, párr. 4.2.1.1.).

Sin embargo, hasta aquí no llega el alcance de este derecho, pues en relación con el principio de doble instancia, la Corte Constitucional expresa que este permite hacer efectivo el acceso a la administración de justicia porque brinda la oportunidad de solicitarle al operador judicial, por parte de quien resulta afectado con una decisión arbitraria o errónea, el restablecimiento y la protección de los derechos que se encuentran contemplados en la constitución y en la ley (Corte Constitucional, 2003).

De lo expuesto, es pertinente resaltar que a partir de la importante labor que ha realizado la Corte Constitucional se evidencia que el acceso a la justicia es un derecho complejo que se encuentra en permanente construcción, en la medida que la jurisprudencia constitucional va estableciendo su concepto, contenido y alcance, labor que hoy en día continúa.

Una mirada doctrinal del acceso a la administración de justicia

Es de gran relevancia aclarar, que los conceptos de acceso a la administración de justicia y acceso a la justicia son distintos, por cuanto el primero necesariamente es consecuencia del segundo, pero no siempre sucede a la inversa ${ }^{3}$, es decir, son términos afines, pero no dejan de ser diferentes (Sánchez-Vallejo, 2017). A pesar de esto, esa íntima relación entre ambos hace que sea necesario observar el desarrollo doctrinal del acceso a la justicia, porque además de ser un tema de gran relevancia, que se ha tratado a lo largo del tiempo por varios jurisconsultos alrededor del mundo, permite crear una visión más amplia, que ayuda a entender la forma y la razón por la cual aparece en la historia.

Según Heim (2014) se tiene la idea de que el desarrollo del término de acceso a la justicia se inauguró con el denominado The Florences Access to Justice Project (El Proyecto Florentino de Acceso a la Justica o Proyecto Florentino), que fue una investigación que planteó un esfuerzo colectivo a nivel internacional, y que también tuvo por objeto estudiar el acceso a la justicia. De allí, se derivó el libro Acceso a la justicia, escrito por Mauro Cappelletti y Bryant Garth ${ }^{4}$. Sin embargo, para Heim (2014) es errada la idea de que la identificación del acceso a la justicia abordada por el proyecto Florentino fue el único origen del movimiento de acceso a la justicia, pues antes de que esta iniciativa cobrara forma, ya existían investigaciones que trataban el acceso a la justicia, aunque no mencionaran este término de una forma literal. Por ello, a modo de ejemplo, Heim menciona la investigación "Law and Society" (Derecho y Sociedad) y las que fueron llevadas a cabo bajo el marco de las teorías jurídicas alternativas o teorías críticas del derecho.

A su vez, dentro del informe "Necesidades jurídicas insatisfechas. Un estudio en el Partido de Moreno", se determinaron dos objetivos fundamentales del acceso a la justicia, a saber:

a) por un lado, permite hacer efectivos los derechos constitucional y legalmente reconocidos y la resolución de conflictos interpersonales y sociales. De esta manera, contribuye a mejorar las condiciones de vida de las personas y, en muchos casos, puede incluso posibilitar un mayor grado

3. Esto, dado que el acceso a la justicia no se limita necesariamente a los mecanismos de defensa judicial.

4. El libro Acceso a la justicia de Mauro Cappelleti y Bryant Garth está disponible en: https://revistas.juridicas.unam.mx/index.php/ derecho-comparado/article/view/2143/2400. 
de autonomía personal; b) por otra parte, posibilita la participación de la sociedad civil en la toma de decisiones y en la instalación en la agenda pública de muchos temas que, de otra manera, no se vehiculizan en los canales institucionales existentes (Böhmer, Fernández \& Freedman, 2005, p. 5).

Ahora bien, cuando se habla del "acceso", observando el contexto, se derivaría de ello la existencia de unas fases que conformarían este derecho. Estos momentos son explicados de manera indistinta por Heim en su tesis doctoral ${ }^{5}$; no obstante, para efectos de este artículo, se pueden clasificar de la siguiente manera:

- Fase pre-procesal: El acceso a la justicia comprende tanto las instancias previas al derecho de acción, que se ve materializado posteriormente en un proceso, como también el uso de mecanismos alternativos de resolución de conflictos, (conciliación, arbitraje, amigable composición, entre otros), que serían otra posible solución a controversias, evitando así el desgaste del aparato jurisdiccional, sin que esto implique que se deje de acceder a la justicia. De no darse lo anterior, debe garantizarse el asesoramiento e información sobre la posibilidad, conveniencia o viabilidad de un proceso.

-Fase procesal: Esta fase incluye no solo el derecho de acceder al proceso y a su desarrollo, sino también el derecho a que el proceso concluya mediante sentencia de fondo, e inclusive, el derecho a su impugnación (incluida la asistencia en las diferentes etapas del litigio y una vez que ha finalizado, la asistencia en la posible apelación de las resoluciones dictadas, o en su revisión u homologación judicial). Al respecto, Fernández Valle (2006) expone que este derecho abarca también el derecho a acceder a información jurídica básica, por vías creativas y de fácil comprensión. La importancia de esto radica en que, como es bien sabido, en general las personas no están familiarizadas con la terminología jurídica, por tanto, debe proveerse una forma en que todos los ciudadanos puedan acceder a ella, pues esto presupone, en palabras de Birgin \& Kohen (2006): "La conciencia del acceso a la justicia como un derecho y la consiguiente obligación del Estado de brindarlo y promoverlo" (p. 20). Lastimosamente, no hay suficientes medios a través de los cuales se pueda facilitar el acceso a una información jurídica mucho más clara para todas las personas, y los que existen no se encuentran repartidos uniformemente en todo el territorio, sino que hay una distribución desigual (las ciudades cuentan con más mecanismos que los pueblos y zonas rurales). "De este modo, los Estados que no prevén soluciones a las diferencias de información con que cuentan sus habitantes, violan este compromiso" (Fernández Valle, 2006, p. 44), al vulnerar el derecho a la igualdad, que está íntimamente relacionado con el acceso a la justicia, pues es un componente esencial de su garantía (Heim, 2014).

-Fase post-procesal: El derecho a su ejecución. El Estado no solo debe garantizar que se dicte una sentencia o providencia judicial, sino que debe procurar su efectivo cumplimiento. Al respecto, Lista (2010) señala: “Un acceso a la justicia centrado en los resultados apunta principalmente a soluciones profesionales, técnicas e instrumentales, en las que prevalece la eficiencia del sistema jurídico propiamente dicho" (p.15).

Por otra parte, en lo que respecta a la concepción internacionalmente aceptada del derecho de acceso a la administración de justicia, que es concebido a su vez como un derecho fundamental,

5. Las fases se encuentran de manera implícita en la p. 41 de la tesis doctoral de Silvia Daniela Heim: "Mujeres y acceso a la justicia de la tradición formalista del derecho a un derecho no androcéntrico”. Disponible en: http://hdl.handle.net/10803/134680 (consultado el 19 de marzo de 2019). 
Borowski (2003) menciona que al derecho estudiado se le puede aplicar la fórmula de los derechos fundamentales, a saber:

Se podría aplicar la fórmula de derechos fundamentales: $<R a b G>$. Donde $<R>$ es el operador jurídico encargado de aplicar este derecho; el sujeto activo, es decir toda persona titular de esta garantía es representada como <a>; el Estado preponderantemente, en sus poderes legislativo y judicial, corresponde $a\langle b\rangle$; y el contenido prestacional de este derecho que tiene lugar antes, durante y después del proceso, es identificado con $<G>$. (p.24).

\section{Obstáculos para acceder a la justicia en Colombia vistos desde la jurisprudencia constitucional}

La soberanía del Estado, en palabras de García Villegas (2008), se puede explicar desde la metáfora de la lámpara como: "Una luz que irradia y controla todo el territorio y toda la población de una nación" (p.8). Esta metáfora suena sensata, pero, tanto en ese momento, como hoy, existen zonas de penumbra que ponen en tela de juicio esta afirmación, tal como ocurre con el acceso a la justicia en la historia colombiana. Verbigracia, se encuentra en un primer momento el abandono estatal, que estuvo presente durante muchos años en sectores como Putumayo, la Guajira, el Guaviare, entre otros, que se hallaban ajenos al control estatal y, por tanto, no contaban con autoridades que atendieran los conflictos que se presentaban allí.

Lamentablemente, dicho abandono representa solo una de las muchas barreras que existen en torno al acceso a la justicia, y pese a que el Estado lo consagró en su ordenamiento jurídico, e intentó darle forma, brindándoles garantías a todas las personas, es evidente que siguen existiendo obstáculos que impiden que se puedan cumplir a cabalidad los mandatos constitucionales. Bajo este entendido, y dada su relevancia, en el presente capítulo se sintetizarán los principales casos hallados en la jurisprudencia constitucional, los cuales para su comprensión se clasificarán de acuerdo con su naturaleza en obstáculos económicos y procesales.

\section{Obstáculos económicos}

Son entendidos para el presente artículo como barreras jurídicas de índole financiero que imposibilitan o limitan el acceso a la administración de justicia de ciertas personas, que, dada su condición económica, se encuentran en incapacidad de acceder al aparato jurisdiccional, o en otros casos, de agotar ciertos mecanismos que se encuentran consagrados en el ordenamiento jurídico nacional.

De acuerdo con lo anterior, encontramos en el año 2004 un caso que ejemplifica una barrera económica en el acceso a la justicia en su fase prejudicial. Donaldo Girón Torres instauró una acción de tutela ante el Juez Segundo Civil Municipal de Buga, solicitando la protección de sus derechos fundamentales al debido proceso, a la igualdad y "a la recta administración", que consideraba vulnerados por parte de la Personería Municipal de Buga, ya que manifiesta que es una persona de escasos recursos que intentó iniciar un proceso de conciliación extrajudicial con la Empresa Proyectos de Infraestructura S.A. (encargada de instalar las señales de tránsito en la región), con el fin de agotar el requisito de procedibilidad que dispone el artículo 35 de la Ley 640 de 2001, para poder reclamar ante la justicia ordinaria una indemnización de perjuicios que le presuntamente le adeudaría dicha entidad, a título de responsabilidad civil 
extracontractual, a causa de un accidente que ocasionó la muerte a su hermano, producto de la ausencia de señalización vial. Sin embargo, pese a que solicitó la conciliación prejudicial en diferentes entidades, como la Cámara de Comercio de la ciudad y las notarías de Buga, no fue posible celebrar dicha audiencia de conciliación de manera gratuita, ya que sus pretensiones eran de mayor cuantía. Igualmente, el consultorio jurídico de la Universidad Central del Valle se negó a realizarla, y como en Buga no hay delegados regionales o seccionales de la Defensoría del Pueblo, ni agentes del Ministerio Público en materia civil, le correspondía a la personería la competencia de manera residual. No obstante, la Personería Municipal de Buga también se negó a llevar a cabo tal diligencia, obstaculizando de esta manera, el derecho de acceso a la administración de justicia del peticionario.

El juez que conoció este caso en primera instancia denegó la tutela y en segunda instancia se confirmó tal decisión. Por lo que, la Corte Constitucional, en sede de revisión, revocó la providencia que fue proferida en primera instancia, y le concedió al peticionario el amparo del derecho de acceso a la administración de justicia, pues consideró que el juez de tutela al exigir que el actor demostrara su condición de pobreza, pese a que manifestó bajo la gravedad del juramento que se encontraba en una situación de precariedad económica, vulneró el principio de la buena fe y: "La regla probatoria según la cual las afirmaciones o negaciones generales e indeterminadas no deben ser probadas, puesto que ello implicaría una carga de imposible cumplimiento" (Corte Constitucional, 2004a). Igualmente, respecto al cobro de ciertas sumas de dinero, para realizar la conciliación en atención al monto de sus pretensiones, la sala estimó que el cumplimiento del fin estatal de facilitar el acceso a las personas de escasos recursos al sistema de administración de justicia, no se puede condicionar a que el monto de las pretensiones formuladas por dichas personas sean de mayor o menor cuantía, en consecuencia, el criterio fundamental que se debe tener en cuenta en estos casos es exclusivamente el de la situación económica del solicitante y, finalmente, en relación con la alternativa que se le otorgó de desplazarse a la ciudad de Cali a un consultorio jurídico, esta corporación manifestó que ello desconocía su condición económica y el deber que tienen las autoridades de interpretar la ley aplicable, de tal forma que contribuya a materializar el derecho de acceso a la administración de justicia, por cuanto el pago de dicho desplazamiento constituye una exigencia desproporcionada, de acuerdo con sus necesidades.

Otro obstáculo económico que se halló en la jurisprudencia constitucional fue en relación con el impuesto de timbre, que en palabras de la Corte Constitucional (2005) es: "Aquel que grava la suscripción de documentos públicos o privados en donde conste la constitución, existencia, modificación o extinción de obligaciones, siempre que las mismas tengan un monto superior a la cifra establecida cada año por el Gobierno Nacional" (párr. 7). En el año 2000, mediante el artículo 109 de la Ley 633, se estableció como agentes retenedores y responsables solidarios a los jueces, conciliadores y tribunales de arbitramento, es decir, se les impuso a los administradores de justicia una carga o condición para la admisión de las demandas, solicitudes de conciliación o convocatoria a tribunales de arbitramento, ya que debían verificar que dentro del proceso obrara el pago del gravamen de los documentos sujetos al impuesto, limitando de esta forma, la posibilidad de los ciudadanos de acceder a administración de justicia. Por esta razón, la Corte Constitucional (2005) declaró inexequible el artículo en mención, pues consideró entre otros argumentos, que desconocía el principio de razonabilidad, ya que la función constitucional de los jueces, conciliadores y tribunales de arbitramento se limitaba a la administración de justicia 
y no a servir de agentes de recaudación, por tanto, pretender que estos asuman funciones de agentes de retención, sin haber participado en el hecho generador del gravamen, es asignarles una obligación evidentemente absurda e insensata, pues los mismos carecen de medios jurídicos para garantizar el pago del impuesto, convirtiéndolos a fin de cuentas en verdaderos contribuyentes responsables económicamente del tributo.

Igualmente, la Corte (2005) estimó que el legislador había desconocido la independencia y autonomía que los jueces tienen en el ejercicio de sus funciones, de acuerdo con el artículo 228 de la Carta Política, de modo que, por ningún motivo, pueden asumir la calidad de partes, siendo responsables del impuesto de timbre. Asimismo, expuso esta corporación, que su exigibilidad obstaculizaba el derecho de acceso a la administración de justicia, pues el derecho y la justicia resultan comprometidos cuando se le asigna un rol a los administradores de ella, que no están llamados a cumplir, desconociéndose de esta forma el principio de proporcionalidad y perdiéndose la independencia y la imparcialidad judicial (artículos 113 y 228 de la Carta Política).

Por otro lado, la Corte analizó la procedencia del recurso extraordinario de casación en materia laboral, el cual según el artículo 86 del Código de Procedimiento Laboral es procedente cuando la cuantía de los procesos excede ciento veinte (120) veces el salario mínimo legal mensual vigente. No obstante, mediante el artículo 48 de la Ley 1395 de 2010 -que adoptó medidas en materia de descongestión judicial-, el legislador aumentó la cuantía a doscientos veinte (220) veces el salario mínimo legal mensual vigente. Por lo tanto, fue declarado inconstitucional, al ser considerado como otra barrera económica de tipo procesal. En este sentido, la Corte Constitucional (2011a) manifestó que el aumento de la cuantía para acceder al recurso, como medida de descongestión judicial, desconocía los principios de razonabilidad y proporcionalidad, ocasionando un sacrificio injustificado de derechos como la igualdad, el acceso a la administración de justicia y las garantías laborales. En este orden de ideas, la Corte estimó que con la norma no solo se vulneró el derecho fundamental de la mayoría de los trabajadores de acceder libremente a la administración de justicia, sino que también, se estableció un trato discriminatorio, toda vez que solo podrían interponer este recurso aquellos trabajadores que contaran con ingresos altos, los cuales son pocos, teniendo en cuenta la estructura salarial del país.

Finalmente, a través de la sentencia C-169 de 2014, se declaró inexequible la Ley 1653 de $2013^{6}$, mediante la cual se regulaba un arancel judicial, el cual es entendido como: "Una contribución parafiscal destinada a sufragar gastos de inversión de la administración de justicia" (Corte Constitucional, 2014b). En este sentido, la Corte Constitucional expone en la providencia mencionada, que deben existir unos límites en la imposición de cargas tributarias que impacten el acceso a la administración de justicia y el derecho de defensa, por cuanto, el arancel judicial introduce un sacrificio desproporcionado: "En los principios de justicia, equidad y progresividad tributarias", vulnerándose de esta manera los derechos consagrados en los artículos 29 y 220 de la Constitución. Por este motivo, la Corte (2014b) concluye que la Ley 1653 de 2013: "Crea una barrera prima facie de acceso a la administración de justicia y de ejercicio de facultades de defensa".

6. Ley 1653 de 2013 , “Por la cual se regula un arancel judicial y se dictan otras disposiciones". Diario Oficial 48852 de julio15 de 2013. Artículo 2. 
Dado lo anterior, es evidente que este derecho constitucional no solo obliga al Estado a proporcionar mecanismos que faciliten el acceso a la administración de justicia, sino que también implica su protección por parte de los operadores judiciales, quienes deben garantizar que todas las personas puedan acceder al aparato jurisdiccional sin importar su posición económica o social.

\section{Obstáculos procesales}

Esta clase de obstáculos pueden definirse como aquellas barreras de tipo jurídico o extrajurídico que las personas encuentran en el transcurso de las diversas etapas procesales. A lo largo del estudio de la jurisprudencia constitucional, se detectaron varios obstáculos que fueron abordados en diferentes providencias. A continuación, se expondrán los casos más representativos:

1) Es pertinente clarificar que en este caso se presenta un obstáculo preprocesal, por cuanto al actor se le vulneró el derecho de acción:

En el año 1993, Leodegar Lorenzo Segundo Roys Reyna instauró acción de tutela contra el jefe de Policía Judicial del Departamento de Policía de la Guajira, por considerar que le fue vulnerado el derecho fundamental a la libertad de conciencia, ya que cuando se presentó ante él para formular una denuncia penal por la desaparición de su hija Eleanor Roys Cotes y no se la recibieron por negarse a prestar juramento, aun cuando informó que su religión le impedía jurar. El Juzgado Segundo Promiscuo de Familia de Riohacha (Guajira) que conoció de la presente acción no concedió la solicitud de tutela, por cuanto estimó que la ley exigía el juramento en la práctica de diligencias judiciales y el hecho de practicar determinada religión no era motivo de excepción, porque se podría incurrir en delitos como la falsa denuncia. El solicitante inconforme, impugnó esta decisión y el Tribunal Superior de Riohacha confirmó el fallo de primera instancia (Corte Constitucional, 1993).

Sin embargo, la Sala de revisión de la Corte Constitucional (1993) estimó que además de presentarse una evidente violación del derecho a la libertad de conciencia del denunciante, también existió una vulneración del derecho al acceso a la administración de justicia, ya que no se le puede dar más importancia a los requisitos formales, que a la necesidad sustancial de una persona de exigir una investigación penal por el presunto secuestro o desaparición de su hija. Por ello, revoca la decisión de primera instancia y concede la tutela. En el marco del Estado social de derecho, los operadores judiciales deben optar por la satisfacción de las exigencias concretas de la justicia material, que de ninguna manera implicaría desestimar de manera infundada los procedimientos jurídicos, sino que, por el contrario, de esta forma se tienden a fallos más justos que evitan: "Que la justicia parezca estrangulada por los lazos de las ritualidades" (Corte Constitucional, 1993, párr. 29).

2) De igual manera, bajo la misma línea de análisis de obstáculos procesales en la fase preprocesal de materialización del derecho, se encuentra el caso de la señora Iveth Patricia Pérez Ramos, quien relató que su madre Aminta Ramos Valenzuela, falleció el 7 de febrero de 2006 en la clínica El Prado de la ciudad de Barranquilla. Agrega que presentó una petición ante la entidad accionada solicitando copia de su historia clínica, ya que en su parecer la causa de la muerte fue la ausencia de prestación oportuna de los servicios de salud por parte de la IPS 
Punto de Salud Boston de Barranquilla. La entidad dio respuesta a la petición argumentando que: "No podía suministrar la historia clínica, por cuanto, esta tiene una reserva legal y solo puede ser entregada al paciente" (Corte Constitucional, 2006). Por tal motivo, instauró una acción de tutela, pues consideró que esta actuación vulneraba sus derechos fundamentales. El juez que conoció en primera instancia denegó el amparo solicitado por estimar que además de que no se cumplía con el requisito de subsidiariedad, tampoco existía vulneración de algún derecho, ya que no era obligación de la entidad dar una respuesta favorable al peticionario. Sin embargo, la Corte Constitucional (2006) conoce esta acción de tutela en sede de revisión, y al hacer un análisis del caso concluye que al no permitírsele a la peticionaria acceder a la historia clínica de su señora madre, se estaría colocando en riesgo su derecho de acceso a la administración de justicia, pues no podría obtener la información que necesitaría para incoar la respectiva acción judicial.

3) Por otro lado, puede evidenciarse en la jurisprudencia barreras de tipo procesal que impiden el acceso a la justicia. Así se observa en el caso de Enna Edith Castillo: "Una mujer enferma, divorciada, de 70 años, que carecía de cualquier tipo de ingreso, por cuanto dependía absolutamente de la caridad de su hijo, quien se encontraba desempleado en aquel momento" (Corte Constitucional, 2011b). Esta persona fue desvinculada ilegalmente del cargo provisional de secretaria que tenía en el Juzgado Tercero Penal Municipal de Barranquilla, y por ello, en junio de 1995, presentó demanda de nulidad y restablecimiento del derecho contra el Consejo Superior de la Judicatura. Sin embargo, el mencionado proceso fue resuelto, en primera instancia, por el Tribunal Administrativo del Atlántico el 13 de agosto de 2008, trece años después de haber presentado la demanda. En esa oportunidad, el tribunal accedió a las pretensiones de la demanda. Pero, esta decisión fue impugnada por el Consejo Superior de la Judicatura, correspondiendo el recurso de apelación a la Sección Segunda del Consejo de Estado, corporación donde se encuentra el expediente para fallo desde el 24 de febrero de 2009 , sin que se haya producido actuación alguna en el curso de dos años. En consecuencia, se instauró una acción de tutela por mora judicial, al considerar la actora que quince años era un término más que razonable para resolver su caso.

Al respecto, en sede de revisión, la Corte Constitucional (2011b) se pronuncia sobre la mora judicial, que es una de las barreras procesales más frecuentes en la administración de justicia. La Corte señaló que la mora judicial afecta los derechos constitucionales fundamentales de acceso a la administración de justicia y a un debido proceso, contemplados en los artículos 29, 228 y 229 de la constitución, por cuanto es deber de las autoridades impulsar las actuaciones y solucionar de manera oportuna los asuntos sometidos a su conocimiento. Por tanto, la dilación injustificada y la inobservancia de los términos judiciales acarrean la vulneración de estos derechos. Sin embargo, la Corte (2011b) argumentó que la mora judicial se justifica cuando la autoridad judicial se encuentra en una situación "imprevisible e ineludible" como el exceso de trabajo, que no le permitan cumplir con los términos señalados por la ley. Por tanto, solo aquella denegación o inobservancia de los términos procesales que se presenten sin causa o razón que los justifiquen, es violatorio del acceso a la administración de justicia y al debido proceso. Por su parte, la mora judicial que configura vulneración de los derechos fundamentales se caracteriza por: 
(i) el incumplimiento de los términos señalados en la ley para adelantar alguna actuación por parte del funcionario competente; (ii) que la mora desborde el concepto de plazo razonable que involucra análisis sobre la complejidad del asunto, la actividad procesal del interesado, la conducta de la autoridad competente y el análisis global de procedimiento; (iii) la falta de motivo o justificación razonable en la demora (Corte Constitucional, 2011b, párr. 31).

No obstante, aunque la mora judicial sea justificada e incluso se hayan adoptado medidas administrativas tendientes a superar el atraso, cuando se afecta a los sujetos de especial protección constitucional, la Corte (2011b) indica que procede una alteración del orden para proferir la decisión judicial, pero que para que se pueda aplicar esta excepción, se requiere que "la controversia tenga relación directa con las condiciones de las que se deriva la calidad de sujeto de especial protección y que, de resultar favorable el fallo, la decisión sea susceptible de incidir favorablemente en tales condiciones".

4) Por otro lado, la Corte hace un análisis de las circunstancias de vulnerabilidad como barrera en el acceso a la justicia en el caso de la señora Pascuas Cifuentes, quien interpone acción de tutela manifestando que, en virtud de su condición de mujer, no fue contratada por parte de una empresa de vigilancia, que fungía como contratista de Ecopetrol S.A., para trabajar como vigilante en la Batería Santa Clara de Ecopetrol. Por su parte, la empresa contratista y Ecopetrol S.A. argumentaron que la señora nunca presentó su hoja de vida a la empresa de vigilancia, razón por la cual fue excluida del proceso de selección.

En primera instancia, el Juzgado Tercero Contencioso Administrativo de Neiva denegó el amparo solicitado, porque estimó que no resultó probada política alguna de discriminación por parte de Ecopetrol o de su contratista SOS Ltda.; por el contrario, adujo que la parte actora no pudo comprobar que:

En desarrollo del proceso de selección de la persona a ocupar el cargo de vigilante, hubiese aportado su hoja de vida, ni tampoco que la misma le haya sido retornada de la forma en que ella describe en la acción (Corte Constitucional, 2010, párr. 16).

Igual consideración tuvo el juez de segunda instancia que confirmó esta decisión. No obstante, la Corte Constitucional, que conoció este caso en sede de revisión, revocó el fallo anterior y concedió el amparo solicitado, por cuanto consideró que resulta inequitativo y contrario al derecho de acceso a la justicia, que la carga probatoria recaiga exclusivamente sobre la persona que alega ser víctima de dicha discriminación, por cuanto es casi imposible probar elementos intencionales por parte de quien realizó la acción presuntamente discriminatoria. Además, en estos casos la protección material del derecho obliga a otorgar un papel especial a los indicios que surjan de lo recaudado en el expediente y, confieren una carga probatoria especial en el acusado, pues estará obligado a demostrar que su conducta garantiza el derecho a la igualdad y, por consiguiente, se aleja por completo de cualquier parámetro que se considere discriminatorio para los sujetos directamente afectados. Igualmente, respecto al acceso a la administración de justicia la Corte manifestó:

Esta es la base conceptual de la exigencia, clara en un Estado social de derecho, que surge para las autoridades públicas respecto de la real concreción de los derechos fundamentales. Y es este el contexto en que debe interpretarse el derecho de acceso a la justicia y, más exactamente, 
el contexto en que deben determinarse los mecanismos que hagan efectiva esta garantía para los asociados. Es por esta razón que adquieren legitimidad mecanismos que equilibren las condiciones que se garantizan a las partes dentro de una disputa ante la administración de justicia, en cualquiera de sus manifestaciones (Corte Constitucional, 2010, párr. 68).

5) Asimismo, frente a las circunstancias de vulnerabilidad, es relevante el caso de un ciudadano privado de la libertad, quien interpone una acción de inconstitucionalidad contra el artículo 31 (parcial) de la Ley 599 de 2000, por cuanto consideró que dicha norma al no definir en números exactos en cuánto aumentaba la pena en un concurso de delitos, vulneraba los artículos 228 y 230 de la Constitución Nacional. El magistrado Luis Ernesto Vargas Silva decidió rechazar la acción pública con base en que el actor, al estar condenado a pena de prisión: "Está inhabilitado legalmente para formularla" (Corte Constitucional, 2015b). Sin embargo, con posterioridad, cuando la Corte resuelve el recurso de súplica interpuesto por el actor, indica que al notificarle por estado esta determinación se le vulneró la garantía procesal a una debida notificación, ya que debía hacerse una excepción a esta regla, por cuanto el demandante se encontraba privado de la libertad en una penitenciaria del país, y la notificación por estados tiene sentido y se encuentra justificada, no solo cuando la parte a quien se le debe surtir está enterada del proceso que se encuentra en curso y cuenta por ello con la carga de vigilarlo; sino además, cuando está en capacidad de cumplir efectivamente con dicha carga, asistiendo al despacho judicial para estar al tanto de los actos procesales, o en algunos casos, mediante la verificación virtual. Por lo tanto, en los procesos de constitucionalidad, cuando la parte actora está confinada en una cárcel o penitenciaría, no tienen la posibilidad efectiva de concurrir a la Corte Constitucional para vigilar el estado del proceso, o de hacer uso de internet, debido precisamente a sus condiciones de encierro. Adicionalmente, en el análisis de este caso, la Corte (2015b) cambia su postura sobre las personas legitimadas para instaurar acciones públicas de constitucionalidad, y sostiene que: "La Constitución les atribuye a los ciudadanos, en general y sin ulteriores precisiones, el derecho a interponer acciones de inconstitucionalidad como una manifestación del derecho fundamental de acceso a la justicia" (párr. 21), por tanto, revoca el auto recurrido en súplica.

6) Adicionalmente, la Corte ha analizado barreras procesales cuando no se han cumplido con las garantías mínimas de un proceso, verbigracia, el derecho a obtener una sentencia de fondo, tal como se vislumbra en el caso de la señora María Inelda Cruz Rodríguez, quien interpone una tutela contra providencia judicial, solicitando el reconocimiento y pago de la pensión de sobrevivientes que no se le reconoció en sede judicial por el traslado del afiliado. Sin embargo, esta fue negada por improcedente por la Sala de Casación Laboral de la Corte Suprema de Justicia, pues estimó que el mecanismo constitucional de amparo previsto en el artículo 86 de la Constitución Política, no podía tornarse en un dispositivo complementario de protección respecto a las decisiones judiciales (Corte Constitucional, 2004c). Además, consideró que carecía de competencia para controvertir las decisiones de otros funcionarios judiciales, ya que tal conducta constituiría un atentado a la seguridad jurídica y a los principios de independencia, autonomía y desconcentración que caracterizan a la administración de justicia. Sin embargo, la Corte Constitucional (2004c) revoca esta providencia, y en su lugar concede los derechos invocados, entre esos el acceso a la administración de justicia, por cuanto concluye que en este asunto procedía la acción de tutela contra decisiones judiciales porque existió una violación directa de la Constitución derivada de la afectación de los derechos fundamentales de una de las partes en el proceso y recalca que las decisiones judiciales inhibitorias, atentan contra el acceso a la administración de justicia. 
7) Finalmente, el máximo organismo de la jurisdicción constitucional ha estudiado el exceso ritual manifiesto como un obstáculo del acceso a la justicia. Así pudo verse en un caso donde el Juzgado Quinto Administrativo del Circuito de Villavicencio negó las súplicas de una demanda de reparación directa, al considerar que, a pesar de haberse demostrado la responsabilidad del Estado a causa de unas fallas en una operación de combate, esta no se podía declarar, porque los demandantes, hijos del soldado fallecido, no acreditaron el parentesco con este; no obstante, un día antes de proferirse dicha sentencia se había allegado al expediente el registro civil de nacimiento de la víctima. En segunda instancia, se confirma tal decisión. Al llegar el caso al tribunal constitucional, este revoca el fallo de primera instancia y concede el amparo del derecho de acceso a la administración de justicia, por cuanto estimó que se incurrió en un defecto procedimental por exceso ritual manifiesto, que en palabras de la Corte Constitucional (2015c):

Se deriva de un fallo en el cual haya una renuncia consciente de la verdad jurídica objetiva evidente en los hechos, por extremo rigor en la aplicación de las normas procesales convirtiéndose así en una inaplicación de la justicia material (párr. 96).

Así como los casos que se relacionaron con anterioridad, se encuentran también otros que permiten concluir, que, a pesar de los avances existentes en el acceso a la administración de justicia, aún se evidencia la presencia de obstáculos en el mismo, generados por agentes estatales, funcionarios judiciales, o incluso, por el mismo legislador. Por ello, es necesaria la presencia de la Corte Constitucional, pues es la entidad judicial que se encarga de velar por la garantía y protección de los derechos fundamentales de todas las personas en el territorio nacional y, particularmente, ha dado contenido y alcance al derecho de acceso a la justicia.

\section{Conclusiones}

1. A través del derecho, los Estados han intentado alcanzar la idea de justicia, de ello, se deriva la razón de ser de los diferentes ordenamientos jurídicos. De la investigación realizada se evidenció, en primer lugar, la evolución que tuvo el acceso a la administración de justicia en la jurisprudencia de la Corte Constitucional, desde el año 1991 hasta el año 2017, recordando inicialmente, que la Constitución de 1886 simplemente contemplaba el servicio de administrar justicia, que estaba a cargo de la Nación, dejando de un lado la forma de acceder a ella, y que por tanto, con la Carta Política de 1991, nace el acceso a la administración de justicia como un derecho fundamental, consagrado expresamente en el artículo 229, y que ha sido reconocido también como un derecho de carácter supranacional, ya que se encuentra consagrado en la Convención Americana sobre Derechos Humanos en el artículo 25 y en el Pacto Internacional de Derechos Civiles y Políticos en el artículo 14, normas que hacen parte integral del ordenamiento jurídico nacional, de conformidad con el artículo 93 de la Constitución. Igualmente, en el marco del acceso a la justicia en esferas internacionales, se encuentra el principio de complementariedad con la Corte Penal Internacional, que permite la lucha contra la impunidad, punto importante para la realización del acceso a la justicia.

2. A partir del año 1991, nace también la Corte Constitucional, quien, actuando como cabeza de la jurisdicción constitucional ha determinado el alcance de las normas que se encuentran contenidas en la Carta Magna, entre ellas, la norma que consagra el acceso a la administración 
de justicia. Por ello, del estudio de la jurisprudencia de esta entidad judicial, se puede extraer, en relación con este derecho fundamental que:

- El artículo 228 de la Constitución contempla la administración de justicia, como una función pública independiente, desconcentrada y autónoma, que le da prevalencia al derecho sustancial. Por su parte, el artículo 229 de la Carta, consagra el derecho de acceso a la administración de justicia, o el también Ilamado "derecho a la tutela judicial efectiva", que implica que todas las personas (naturales y jurídicas), en un plano de igualdad, tienen la posibilidad de acudir ante los jueces y tribunales de justicia, para defender el ordenamiento jurídico y buscar el restablecimiento y protección de sus derechos y garantías, con sujeción a los procedimientos legales y con la observancia de las garantías sustanciales y procedimentales.

- Es evidente la estrecha relación que existe entre el derecho de acceso a la administración de justicia y el debido proceso, ya que el segundo, hace parte integral del núcleo esencial del primero; por ello, cuando el derecho al debido proceso es vulnerado por las autoridades judiciales se atenta directamente contra el derecho de acceso a la administración de justicia, pues se encuentran necesariamente ligados y son interdependientes entre sí. Sin embargo, la Corte considera que el acceso a la administración de justicia es un derecho medular de contenido múltiple, dado su vínculo con otros derechos constitucionales como la igualdad, la libertad, etc., y bajo este entendido, implica el derecho de acción, que es la posibilidad de ser parte de un proceso y a través de los diferentes instrumentos plantear las pretensiones al Estado; el derecho a que en el curso del proceso se respeten las garantías procesales mínimas, entre ellas, a que se concluya con una decisión de fondo sobre las pretensiones, el derecho a que los procedimientos sean adecuados, idóneos y efectivos, el derecho a que el proceso se surta en un término razonable, sin dilaciones injustificadas y observando el debido proceso; finalmente, implica el derecho a que una vez finalizado el proceso se dé cumplimiento a la decisión judicial. Ahora bien, del análisis de la jurisprudencia de la Corte Constitucional también se puede concluir que el derecho estudiado es complejo dado que existen matices conceptuales y múltiples interpretaciones sobre el alcance y contenido de este derecho constitucional.

-Los postulados constitucionales del artículo 228 y 229, se encuentran desarrollados en la ley estatutaria de administración de justicia “Ley 270 de 1996", que establece, entre otros aspectos, los principios orientadores de esta función pública, que incluyen: el acceso a la justicia de todos los asociados, adoptando para tal efecto mecanismos que facilitan un acceso gratuito a las personas de escasos recursos, como el amparo de pobreza y la defensoría pública; el derecho a la defensa, que en ciertos casos es atribuido a los consultorios jurídicos de las universidades; el principio de celeridad, oralidad, eficiencia y los mecanismos alternativos de solución de conflictos, como la conciliación y el arbitraje. Igualmente, el acceso a la administración de justicia se puede ver reflejado en distintos mecanismos judiciales introducidos al ordenamiento jurídico como ocurre con la acción de tutela, con el proceso monitorio que facilita la celeridad o con el curador ad litem que permite que se garantice este derecho a quien no está presente en un proceso judicial.

2. En la doctrina también se encontraron importantes aportes en relación con el acceso a la justicia. Por ejemplo, a partir de allí se pudieron determinar las tres fases que comprende este derecho, a saber: la fase preprocesal, donde se encuentra el asesoramiento sobre el eventual proceso y los mecanismos alternativos de solución de conflictos; la fase procesal que incluye 
el derecho a acceder al proceso, a que se desarrolle y concluya con una decisión de fondo y el derecho en ciertos casos a la impugnación; y finalmente, la fase postprocesal que hace referencia al cumplimiento efectivo de las sentencias judiciales. Estas contribuciones doctrinales, permiten demostrar la relevancia de este derecho, en el campo de estudio del conocimiento jurídico.

3. A pesar de que este derecho fundamental tiene gran relevancia constitucional, legal, e incluso internacional, existen obstáculos, que en muchos casos limitan o impiden el libre acceso a la administración de justicia, unos de índole económico que obstruyen el acceso de las personas, debido a las exigencias de carácter patrimonial, y otros de carácter procesal, como el exceso ritual manifiesto, la mora judicial, las dilaciones injustificadas, las decisiones inhibitorias, el desconocimiento por parte de los operadores judiciales de la Constitución, la ley, la jurisprudencia e incluso el derecho internacional, entre otros, que dan cuenta no solo de los errores en que incurren los funcionarios judiciales al momentos de administrar justicia, sino también del incumplimiento de los principios rectores de la administración de justicia, como son la celeridad y la eficacia.

Por lo anterior, es evidente la necesidad de realizar cambios significativos y conscientes al interior de la administración de justicia, puesto que, lamentablemente, los mecanismos que se han implementado en la rama judicial, por ejemplo, para agilizar los procesos, resultan contraproducentes. Tal es el caso de los centros de servicios judiciales, que aunque se crearon con el fin de apoyar algunos juzgados, por el contrario, han ocasionado tropiezos al momento de prestar esta función pública, ya que desde que se implementaron, los despachos judiciales se quejan de las constantes demoras y del exceso de trabajo, que en muchos casos, excede la capacidad humana de los funcionarios judiciales, por cuanto se evidencia más congestión judicial, esto, en razón a que su creación implicó que se suprimieran algunos cargos de la rama judicial, y por tanto, los pocos empleados que quedaron en algunos juzgados deben suplir la mayoría de las funciones que cumplían los demás. Esto, impide que haya celeridad en el impulso procesal. Asimismo, las reformas de los requisitos para ser funcionario de la rama judicial no son acordes con las necesidades de la administración de justicia, pues actualmente, para ser auxiliar judicial grado 4 se requiere ser técnico en sistemas, olvidándose de esta manera, lo esencial que es el derecho en la administración de justicia, pues es a través de este que se materializa la justicia.

De acuerdo con lo anterior, es pertinente resaltar, a modo de conclusión, que se deben implementar estrategias que intenten especialmente dar solución a las necesidades reales que tiene la administración de justicia, para así, poder garantizar a todas las personas un acceso ágil, oportuno, seguro, respetuoso y efectivo.

\section{Referencias bibliográficas}

Birgin, H., \& Kohen, B. (2006). Acceso a la justicia como garantía de igualdad: instituciones, actores y experiencias comparadas. Recuperado de: https://books.google.com.co/ books/about/Acceso_a_la_justicia_como_garant\%C3\%ADa_de_i.html?id=-YfatUXpwq4C\&redir_esc=y (Consultado el 3 de mayo de 2019).

Böhmer, M., Pujó, S., Fernández Valle, M., \& Freedman, D. (2005). Necesidades Jurídicas 
Insatisfechas: Un estudio en el Partido de Moreno. Obtenido de: Biblioteca Virtual Centro de Estudios de Justicia de las Américas. http://biblioteca.cejamericas.org/handle/2015/2885?show=full

Borowski, M. (2003). La estructura de los derechos fundamentales. (Bernal, C. Trad.) Bogotá: Universidad Externado de Colombia.

Congreso de Colombia. (29 de diciembre de 2000) Ley de reforma tributaria. [Ley 633 de 2000]. Diario Oficial 44275. Disponible en: https://www.funcionpublica.gov.co/eva/ gestornormativo/norma.php?i=6285

CorteConstitucional.(26denoviembrede1993)SentenciaT-547. [MPAlejandroMartínezCaballero]. Disponible en: https://www.corteconstitucional.gov.co/relatoria/1993/T-547-93.htm

Corte Constitucional. (5 de febrero de 1996a) Sentencia C-037. [MP Vladimiro Naranjo Mesa]. Disponible en: https://www.corteconstitucional.gov.co/relatoria/1996/C-037-96.htm

Corte Constitucional. (18 de junio de 1996b) Sentencia T-268. [MP Antonio Barrera Carbonell]. Disponible en: https://www.corteconstitucional.gov.co/relatoria/1996/T-268-96.htm

Corte Constitucional. (8 de septiembre de 1998) Sentencia T-476. [MP Fabio Morón Díaz]. Disponible en: https://www.corteconstitucional.gov.co/relatoria/1998/T-476-98.htm

Corte Constitucional. (29 de mayo de 2002a) Sentencia C-426. [MP Rodrigo Escobar Gil]. Disponible en: https://www.corteconstitucional.gov.co/relatoria/2002/C-426-02.htm

Corte Constitucional. (30 de julio de 2002b) Sentencia C-578. [MP Manuel José Cepeda Espinosa]. Disponible en: https://www.corteconstitucional.gov.co/relatoria/2002/C-578-02.htm

Corte Constitucional. (11 de febrero de 2003) Sentencia C-095. [Rodrigo Escobar Gil]. Disponible en: https://www.corteconstitucional.gov.co/relatoria/2003/C-095-03.htm

Corte Constitucional. (22 de octubre de 2004a) Sentencia T-1044. [MP Manuel José Cepeda Espinosa]. Disponible en: https://www.corteconstitucional.gov.co/ relatoria/2004/T-1044-04.htm

Corte Constitucional. (4 de marzo de 2004b) Sentencia T-192. [MP Marco Gerardo Monroy Cabra]. Disponible en: https://www.corteconstitucional.gov.co/relatoria/2004/T-192-04.htm

Corte Constitucional. (18 de febrero de 2004c) Sentencia T-134. [MP Jaime Córdoba Triviño]. Disponible en: https://www.corteconstitucional.gov.co/relatoria/2004/T-134-04.htm

Corte Constitucional. (24 de mayo de 2005) Sentencia C-543. [MP Rodrigo Escobar Gil]. Disponible en: https://www.corteconstitucional.gov.co/relatoria/2005/C-543-05.htm

Corte Constitucional. (12 de octubre de 2006) Sentencia T-834. [MP Nilson Pinilla Pinilla]. Disponible en: https://www.corteconstitucional.gov.co/relatoria/2006/T-834-06.htm 
Corte Constitucional. (15 de abril del 2010) Sentencia T-247. [MP Humberto Antonio Sierra Porto]. Disponible en: https://www.corteconstitucional.gov.co/relatoria/2010/T-247-10.htm

Corte Constitucional. (12 de mayo de 2011a) Sentencia C-372. [MP Jorge Ignacio Pretelt Chaljub]. Disponible en: https://www.corteconstitucional.gov.co/relatoria/2011/c-372-11.htm

Corte Constitucional. (20 de septiembre de 2011b) Sentencia T-693A. [MP Gabriel Eduardo Mendoza Martelo]. Disponible en: https://www.corteconstitucional.gov.co/ relatoria/2011/T-693A-11.htm

Corte Constitucional. (15 de mayo de 2013a) Sentencia C-279. [MP Jorge Ignacio Pretelt Chaljub]. Disponible en: https://www.corteconstitucional.gov.co/relatoria/2013/C-279-13.htm

Corte Constitucional. (17 de abril de 2013b) Sentencia C-222. [MP María Victoria Calle Correa]. Disponible en: https://www.corteconstitucional.gov.co/relatoria/2013/c-222-13.htm

Corte Constitucional. (16 de mayo de 2013c) Sentencia T-283. [MP Jorge Ignacio Pretelt Chaljub]. Disponible en: https://www.corteconstitucional.gov.co/relatoria/2013/T-283-13.htm

Corte Constitucional. (11 de junio de 2014a) Sentencia C-367. [MP Mauricio González Cuervo]. Disponible en: https://www.corteconstitucional.gov.co/relatoria/2014/C-367-14.htm

Corte Constitucional. (19 de marzo de 2014b) Sentencia C-169. [MP María Victoria Calle Correa]. Disponible en: https://www.corteconstitucional.gov.co/relatoria/2014/C-169-14.htm

Corte Constitucional. (12 de febrero de 2014) Sentencia C-083. [MP María Victoria Calle Correa]. Disponible en: https://www.corteconstitucional.gov.co/relatoria/2014/C-083-14.htm

Corte Constitucional. (11 de junio de 2014) Sentencia C-369. [MP Alberto Rojas Ríos]. Disponible en: https://www.corteconstitucional.gov.co/relatoria/2014/C-369-14.htm

Corte Constitucional. (1 de julio de 2015a) Sentencia C-410. [MP Alberto Rojas Ríos]. Disponible en: https://www.corteconstitucional.gov.co/RELATORIA/2015/C-410-15.htm

Corte Constitucional. (10 de junio de 2015b) Auto 241. [MP María Victoria Calle Correa]. Disponible en: https://www.corteconstitucional.gov.co/relatoria/autos/2015/A241-15.htm

Corte Constitucional. (3 de junio de 2015c) Sentencia T-339. [MP Jorge Iván Palacio Palacio]. Disponible en: https://www.corteconstitucional.gov.co/relatoria/2015/T-339-15.htm

Corte Constitucional. (29 de agosto de 2016a) Sentencia T- 461. [MP Jorge Iván Palacio Palacio]. Disponible en: https://www.corteconstitucional.gov.co/relatoria/2016/t-461-16.htm

Corte Constitucional. (6 de abril de 2016b) Sentencia C-159. [MP Luis Ernesto Vargas Silva]. Disponible en: https://www.corteconstitucional.gov.co/relatoria/2016/C-159-16.htm

Corte Constitucional. (9 de noviembre de 2016c) Sentencia T-616. [MP Jorge Iván Palacio Palacio] Disponible en: https://www.corteconstitucional.gov.co/relatoria/2016/t-616-16.htm 
Fernández Valle, M. (2006). El acceso a la justicia de los sectores en desventaja económica y social. Recuperado de: https://www.academia.edu/12314084/_El_acceso_a_la_ justicia_de_los_sectores_en_desventaja_econ\%C3\%B3mica_y_social_

García Villegas, M. (2008). Jueces sin Estado: la justicia colombiana en zonas de conflicto armado. Bogotá: DeJusticia.

Heim, S. D. (2014). Mujeres y acceso a la justicia: de la tradición formalista del derecho a un derecho no androcéntrico. (Tesis doctoral, Universidad Autónoma de Barcelona). Recuperado de http://hdl.handle.net/10803/134680

Kelsen, H. (1949). Teoría general del derecho y el estado. México.

Lista, C. (2010). Prólogos. En S. Boueiri Bassil, El acceso a la justicia: contribuciones teórico-empíricas en y desde países latinoamericanos. Madrid: Dykinson.

Organización de Estados Americanos. (22 de Noviembre de 1969). Convención Americana de Derechos Humanos. Obtenido de https://www.oas.org/dil/esp/tratados_b-32_ convencion_americana_sobre_derechos_humanos.htm

Organización de Naciones Unidas. (16 de diciembre de 1966). Pacto Internacional de Derechos Civiles y Políticos.. Disponible en: https://www.ohchr.org/SP/Professionallnterest/ Pages/CCPR.aspx (Consultado el 22 de febrero de 2019).

Rama Judicial de Colombia. (s.f.). La Corte. Disponible en: ramajudicial.gov.co/en/web/ corte-constitucional/portal/corporacion/corte 